\title{
EVALUATION OF THE EFFECTS OF CAPSULES CONTAINING TRIBULUS TERRESTRIS EXTRACT AND L- CARNITINE ON TREATMENT OF OLIGOSPERMIA IN MALES
}

\author{
Mahmoudi Hossein'1, Akbari Hossein², Taghizade Mohsen³, Jahangirian Jamileh", Mohboobi Mohadese ${ }^{5}$, Mahlooji Mahnaz $^{6}$ \\ ${ }_{1}^{1}$ Assistant Professor, Department of Surgery, Faculty of Medicine, Kashan University of Medical Sciences, Kashan, Iran. \\ ${ }^{2}$ Assistant Professor, Social Determinants of Health (SDH) Research Center, Kashan University of Medical Sciences, Kashan, Iran. \\ ${ }^{3}$ Associate Professor, Research Center of Biochemistry and Nutrition in Metabolic Diseases, Kashan University of Medical Sciences, \\ Kashan, Iran \\ ${ }^{4}$ General Practitioner, Qom University of Medical Sciences, Qom, Iran. \\ ${ }^{5}$ Researcher in Research and Development Center, Barij Essence Company, Kashan, Iran. \\ ${ }^{6}$ Researcher in Research and Development Center, Barij Essence Company, Kashan, Iran.
}

\begin{tabular}{l}
\hline ABSTRACT \\
BACKGROUND \\
Infertility is defined as failure to achieve pregnancy after one year of unprotected sexual intercourse. Male infertility is one of the \\
most challenging problems in andrology. The common cause of male infertility is related to disorders in sperm production. In this \\
study for the first time, effect of combination Tribulus terrestris extract and L-carnitine on sperm parameters of infertile men were \\
reviewed.
\end{tabular}

\section{MATERIALS AND METHODS}

This double-blind study was conducted on 61 men, 25 to 40 years old with infertility due to sperm abnormalities on semen analysis parameters (Criteria WHO). They were randomly assigned to two groups of $350 \mathrm{mg}$ herbal capsules containing Tribulus terrestris extract + L-carnitine (Intervention) or $350 \mathrm{mg}$ placebo capsules (Control) 4 times a day for 3 months. At the beginning and end of the study, semen analysis and serum levels of FSH, LH and testosterone were evaluated, and results were compared between the groups with baseline.

\section{RESULTS}

The results showed that after three months of intervention in control group, no significant change in semen analysis parameters and levels of FSH, LH and testosterone happened ( $p>0.5)$. In the intervention group, only Progressive index in semen analysis (28.6 vs 33.2) from baseline showed statistically significant changes $(p=0.033)$. The difference of efficacy between intervention and control groups before and after the study was not significant in any of the parameters.

\section{CONCLUSION}

Based on the results of this study, treatment with herbal capsule containing Tribulus terrestris extract and L-carnitine for three months in the improvement of abnormal sperm parameters in infertile men is not effective.

\section{KEY WORDS}

Tribulus Terrestris, L-Carnitine, Infertility, Semen Analysis, Oligospermia.

HOW TO CITE THIS ARTICLE: Hossein M, Hossein A, Mohsen T, et al. Evaluation of the effects of capsules containing tribulus terrestris extract and L-carnitine on treatment of oligospermia in males. J. Evolution Med. Dent. Sci. 2018;7(29):3266-3269, DOI: $10.14260 /$ jemds/2018/736

\section{BACKGROUND}

Infertility is the inability to conceive after a one year period with regular and unprotected sex.[1] About 15\% of the couples are exposed to infertility complications by the end of their first year of marriage.[2] In Iran about one-third of the married couples experience primary infertility, that is about the global average rate.[3] In $40 \%$ of the cases infertility results from male factor, in $40 \%$ female factor and the remaining is due to both male and female factors. ${ }^{[4]}$ Some known factors contributing to this complication are hormonal and chromosomal disorders, testicular abnormalities,

'Financial or Other Competing Interest': None.

Submission 03-06-2018, Peer Review 28-06-2018,

Acceptance 04-07-2018, Published 14-07-2018.

Corresponding Author:

Jahangirian Jamileh,

General Practitioner,

Qom University of Medical Sciences,

Qom, Iran Post Code-3716693139.

E-mail:dr.jahangirian@gmail.com

DOI: $10.14260 /$ jemds $/ 2018 / 736$

\section{(c) $(1) \$$}

disruption of spermatogenesis, inflammation, varicocele, sperm dysfunction, kidney, liver and blood diseases, poisons, drugs and radiation.[5] Oligospermia and low-quality of sperms are responsible for more than $90 \%$ of male infertility cases.[6] Male infertility treatments include public, pharmacological and surgical supports. Pharmacological treatments comprise of gonadotropins, androgens, corticosteroids, antibiotics and anticholinergics, antiestrogens as well as alternative treatments such as antioxidants (Multivitamins) and L-carnitine which is the safest therapeutic method.[7] Different studies reported efficacy of L-carnitine in infertile males with abnormal sperm parameters,[8,9] although some other studies indicated inefficacy of L-carnitine in volume and normal morphology of spermatozoa.[10] Comparison of the levels of L-carnitine in fertile and infertile males showed that its level was significantly lower in infertile males than the fertile ones, hence relieving of this deficiency may influence infertility in such patients.[11] Tribulus terrestris is one of the popular plants known in the treatment of male sexual complications. Evidence showed that Tribulus terrestris can directly elevate 
spermatogenesis by increasing the number of Leydig cells and production of androgens.[12-15] Also, Tribulus terrestris extract can affect the morphology and number of sperms in rats,[13] although some other studies reported inefficacy of Tribulus terrestris extract on the number of spermatozoa in rats in spite of improvement in sexual behaviours and increased level of testosterone.[14] Owing to the efficacy of the aforementioned two components in the morphology and motility of spermatozoa and contradiction in the results of different studies in this field, the current study aimed at evaluating the effect of simultaneous consumption of these compounds on males with infertility.

\section{MATERIALS AND METHODS}

\section{Study Design}

The current randomised, clinical trial was approved by the Ethics Committee of Kashan University of Medical Sciences (P/29/5/1/4766 date 2015/01/07).

\section{Participants}

Males with infertility within the age range of 25 to 40 years referring to the under-study urology clinic in 2016 that met the World Health Organization (WHO) criteria as reporting one of the following complications in two semen analyses were considered as infertile: sperm number less than $20 \times 106 / \mathrm{mL}$, total motility $<50 \%$, progressive motility $<25 \%$ and normal sperm morphology $<30 \%$.

\section{Exclusion Criteria}

The exclusion criteria were the history of infertility for less than one year, abnormal levels of gonadotropins, testosterone and prolactin, azoospermia, urinary tract obstruction or infection, varicocele grade 3 or 4 , testicular atrophy, ejaculation disorders, endocrine or anatomic disruption, underlying disease, severe allergy to L-carnitine and Tribulus terrestris, being a candidate for intracytoplasmic sperm injection (ICSI) due to severe spermiogram abnormalities, sexual complications and taking contraceptives within the past three months.

\section{Sample Size}

Based on the results of different studies, the effect of Lcarnitine on the number of spermatozoa was evident and increased from $44.75 \pm 18.1$ to $73.25 \pm 18.5$; hence, the sample size was set to 35 based on $95 \%$ confidence and power test of $90 \%$.

\section{Data Collection Method}

Patients referring to the clinic were enrolled in the study after diagnosis and meeting the inclusion/ exclusion criteria. They were asked to sign the informed consent form prior to completing a questionnaire containing demographic characteristics, disease status, the results of the last semen analysis test and serum level of LH and FSH. They were accordingly assigned into either the intervention or placebo group. Group intervention received herbal capsules containing Tribulus terrestris extract plus L-carnitine. The placebo group received placebo in the same shape and colour, both made by Barij Essence Company. The intervention lasted for three months four times a day. To blind the subjects in both groups, the given packs of capsules were encoded and not decoded before saturation of samples and data collection.
The packs of capsules were coded based on the random block effects using random number tables with quadrant blocks. Adherence to the treatment and side effects were evaluated monthly by a nurse on telephone and the results were recorded in the questionnaires. After three months of intervention, the subjects were visited and semen analysis as well as LH and FSH levels was tested; inter- and intra-group comparisons were performed based on the pretest and posttest results. For semen analysis the subjects were asked to prevent ejaculation 48 hours to seven days prior to testing. To obtain conclusive results, two semen analyses with a fourweek interval were performed. Analysis was performed immediately after the sampling.

\section{Statistical Analysis}

The normality of dependent variables was evaluated using the Kolmogorov-Smirnov test. Then, based on the qualitative or quantitative data, the paired t-test or McNemar's tests were used to evaluate the effects of each group and compare the groups, the independent t-test, chi-square or the Fisher's exact test were employed.

\section{RESULTS}

The current study evaluated 61 patients with fertility disorders; 28 subjects in the placebo and 33 in the intervention groups. The Mean \pm SD of the patients in the intervention and control groups were $31.8 \pm 6.02$ and 31.6 \pm 5.4 years, respectively $(\mathrm{p}=0.9)$. No significant differences were observed between the groups in terms of the level of education, occupational status, weight, height, spouse age and duration of marriage $(p>0.6)$. In addition, there was no significant association between the study subjects and familial history of infertility, history of alcohol consumption and smoking, and sexual diseases and complications $(p>0.3)$ (Table 1).

The mean total sperm count was 163.9 in the placebo group which increased to 188.3 after the intervention, while they were 147.3 and 149.1 in the intervention group respectively. No significant changes were observed between pre-intervention and post-intervention measures in the two study groups $(\mathrm{p}>0.554)$. No significant differences were observed in the placebo group before and after the intervention in terms of other indices ( $p>0.44)$. There was a significant difference in progressive motility index before and after the intervention in the intervention group and in terms of other indices no significant difference was observed ( $>0.13$ ) (Table 2). The mean total sperm count increased to 11.75 million and 4.4 million in the intervention and placebo groups compared with the pre-intervention counts, respectively, although no significant difference was observed between the groups $(\mathrm{p}=0.27)$. There was also no significant difference between the groups in terms of other indices regarding the fertility profile $(\mathrm{p}>0.19)$ (Table 3 ).

\begin{tabular}{|c|c|c|c|c|}
\hline \multicolumn{2}{|c|}{ Variables } & $\begin{array}{c}\text { Placebo } \\
(n=33)\end{array}$ & $\begin{array}{c}\text { Herbal Drug } \\
(\mathbf{n = 2 8 )}\end{array}$ & P value \\
\hline \multirow{2}{*}{$\begin{array}{c}\text { Age } \\
\text { (year) }\end{array}$} & $30<$ & $11(39.3)$ & $14(42.4)$ & \multirow{2}{*}{0.8041} \\
\cline { 2 - 5 } & $30 \geq$ & $17(60.7)$ & $19(57.6)$ & \\
\cline { 2 - 4 } Gean \pm SD & $31.6 \pm 5.4$ & $31.8 \pm 6.02$ & 0.92 \\
\hline \multirow{2}{*}{ Graduate } & $\begin{array}{c}\text { Diploma and } \\
\text { Less }\end{array}$ & $21(75)$ & $23(69.7)$ & \multirow{2}{*}{$0.905^{1}$} \\
\cline { 2 - 4 } & Academic & $7(25)$ & $10(30.3)$ & \\
\hline
\end{tabular}




\begin{tabular}{|c|c|c|c|c|}
\hline \multirow{3}{*}{ Job } & Free & $14(50)$ & $19(57.6)$ & \multirow{2}{*}{$0.698^{1}$} \\
\cline { 2 - 4 } & Employee & $7(25)$ & $7(21.2)$ & \\
\cline { 2 - 4 } & $\begin{array}{c}\text { Manual } \\
\text { Worker }\end{array}$ & $6(21.4)$ & $7(21.2)$ & \\
\hline \multicolumn{2}{|c|}{ Weight (kg) } & $77.8 \pm 13.5$ & $79.7 \pm 16.3$ & $0.635^{1}$ \\
\hline Height (cm) & $173.2 \pm 7.5$ & $176.5 \pm 8.02$ & $0.104^{1}$ \\
\hline Spouse's Age & $28.2 \pm 5.3$ & $27.3 \pm 4.3$ & $0.463^{1}$ \\
\hline Term of Marriage & $5.25 \pm 3.57$ & $6.9 \pm 5.2$ & $0.151^{1}$ \\
\hline $\begin{array}{c}\text { Family history of } \\
\text { Infertility }\end{array}$ & $3(10.7)$ & $6(18.2)$ & $0.488^{1}$ \\
\hline History of the Disease & $7(25)$ & $5(15.2)$ & $0.335^{1}$ \\
\hline Sexual Dysfunction & $1(3.6)$ & $1(3)$ & N.S1 \\
\hline
\end{tabular}

Table 1. Frequency of Studied Groups according to Demographic and Disease Characteristics

${ }^{1}$ Chi-square test, ${ }^{2}$ Independent samples T-test.

\begin{tabular}{|c|c|c|c|c|c|c|}
\hline \multirow[b]{2}{*}{$\begin{array}{l}\text { Fertility } \\
\text { Profiles }\end{array}$} & \multicolumn{3}{|c|}{ Placebo } & \multicolumn{3}{|c|}{ Herbal Drug } \\
\hline & Before & fter & $\begin{array}{c}P \\
\text { valu } \\
\mathrm{e}^{1}\end{array}$ & Before & After & \begin{tabular}{|c|}
$\mathbf{P}$ \\
valu \\
$\mathrm{e}^{1}$
\end{tabular} \\
\hline & 9 & $\begin{array}{l}68.3 \pm 23 \\
7.5\end{array}$ & $\begin{array}{c}0.77 \\
8\end{array}$ & & $\begin{array}{l}49.1 \pm 7 \\
2.9\end{array}$ & $\begin{array}{c}0.55 \\
4\end{array}$ \\
\hline & $39.7 \pm 38.6$ & $38.5 \pm 44.7$ & \begin{tabular}{|c|}
0.84 \\
4 \\
\end{tabular} & \begin{tabular}{|c|}
$40.2 \pm 32$ \\
8 \\
\end{tabular} & $\begin{array}{c}40.03 \pm 3 \\
0.6 \\
\end{array}$ & \begin{tabular}{|c}
0.98 \\
1 \\
\end{tabular} \\
\hline Volu & $3.75 \pm 1.9$ & $3.9 \pm 1.6$ & 0.66 & $3.59 \pm 1.9$ & $3.66 \pm 1.8$ & $\begin{array}{c}0.78 \\
7\end{array}$ \\
\hline Moti & $\begin{array}{c}41.28 \pm 19 \\
4\end{array}$ & $\begin{array}{c}42.39 \pm 18 \\
1\end{array}$ & 0.44 & $\begin{array}{c}40.4 \pm 15 \\
9\end{array}$ & $\begin{array}{c}44.1 \pm 17 \\
5\end{array}$ & 0.13 \\
\hline essi & $\begin{array}{c}27.53 \pm 16 \\
5\end{array}$ & $\begin{array}{c}27.07 \pm 19 \\
4\end{array}$ & 0.74 & \begin{tabular}{|c|}
$28.7 \pm 13$ \\
2
\end{tabular} & $\begin{array}{c}33.2 \pm 16 \\
8\end{array}$ & $\begin{array}{c}0.03 \\
3 \\
\end{array}$ \\
\hline $\begin{array}{c}\text { Morpholo } \\
\text { gy }\end{array}$ & $\begin{array}{c}49.71 \pm 21 \\
5 \\
\end{array}$ & $\begin{array}{c}50.57 \pm 18 \\
5\end{array}$ & 0.85 & \begin{tabular}{|c|}
$43.6 \pm 21$ \\
8 \\
\end{tabular} & $\begin{array}{c}43.1 \pm 22 \\
3 \\
\end{array}$ & \begin{tabular}{|c}
0.82 \\
4 \\
\end{tabular} \\
\hline & $5.42 \pm 3.8$ & $5.67 \pm 4.7$ & $\begin{array}{c}0.70 \\
5\end{array}$ & $4.11 \pm 1.3$ & $4.29 \pm 1.3$ & $\begin{array}{c}0.17 \\
3\end{array}$ \\
\hline & $64 \pm 3.3$ & $4.62 \pm 3.4$ & 0.95 & $4.52 \pm 1.9$ & $4.42 \pm 1.8$ & 0.48 \\
\hline & $5.68 \pm 2.7$ & $5.47 \pm 2.8$ & $\begin{array}{c}0.60 \\
7\end{array}$ & $5.26 \pm 1.9$ & $5.11 \pm 2$ & $\begin{array}{c}0.63 \\
6\end{array}$ \\
\hline
\end{tabular}

Table 2. Mean and Standard Deviation of Fertility Profiles based on Semen Analysis in patients treated with Placebo and Herbal Drug before and after Treatment

1Paired samples T-test.

\begin{tabular}{|c|c|c|c|}
\hline $\begin{array}{c}\text { Fertility } \\
\text { Profiles }\end{array}$ & $\begin{array}{c}\text { Placebo } \\
\text { (n=33) }\end{array}$ & $\begin{array}{c}\text { Herbal Drug } \\
\text { (n=28) }\end{array}$ & P value $^{\mathbf{1}}$ \\
\hline Count $\left(10^{6}\right)$ & $11.75 \pm 4.52$ & $4.4 \pm 3.27$ & 0.27 \\
\hline $\begin{array}{c}\text { Count per } \mathrm{mL} \\
\left(10^{6}\right)\end{array}$ & $-0.12 \pm 1.09$ & $-1.2 \pm 0.75$ & 0.575 \\
\hline Volume & $0.06 \pm 0.568$ & $0.15 \pm 0.75$ & 0.594 \\
\hline Motility & $3.69 \pm 2.25$ & $1.11 \pm 1.12$ & 0.401 \\
\hline Progressive & $4.52 \pm 1.23$ & $-0.46 \pm 0.89$ & 0.185 \\
\hline Morphology & $0.51 \pm 1.24$ & $0.86 \pm 1.17$ & 0.19 \\
\hline LH & $0.18 \pm 0.65$ & $0.25 \pm 2.17$ & 0.245 \\
\hline FSH & $-0.1 \pm 0.84$ & $-0.02 \pm 0.65$ & 0.771 \\
\hline T & $-0.15 \pm 1.14$ & $-0.21 \pm 1.85$ & 0.908 \\
\hline
\end{tabular}

Table 3. Mean and Standard Deviation of changes in Male Fertility Profile after treatment in Two Groups

1Independent samples T-test.

\section{DISCUSSION}

Results of the current study indicated that the consumption of placebo for three months caused no significant changes in semen analysis parameters. In a clinical trial conducted by Peyvandi et al, a two-month consumption of placebo caused no significant changes in spermiogram parameters of males with infertility.[10]

In the current study, a significant difference was observed between the pre- and post-intervention measures only in the progressive motility index in the intervention group and there were no significant changes between pre- and postintervention measures regarding other indices. In addition, there was no significant difference in serum levels of LH and FSH as well as testosterone between the pre- and postintervention measures in the two study groups. Setiawan in a clinical trial administered $500 \mathrm{mg}$ of Tribulus terrestris extract three times a day for 60 days to 30 males with infertility, and reported a significant increase in the number of slow progressive spermatozoa and a significant decrease in the number of non-motile spermatozoa.[16] In the study by Peyvandi et al, two months administration of L-carnitine to males with infertility increased the progressive motility of spermatozoa.[10] Different clinical trials ${ }^{[9,17-20]}$ and pharmacological studies ${ }^{[12,15,21]}$ showed that the consumption of L-carnitine and Tribulus terrestris extract could improve sperm parameters and consequently result in infertility treatment. The results were inconsistent with those of the current study. Contradiction between the findings of the mentioned studies and those of the current one can be attributed to different sample sizes, duration of study or administered dosage; however, co-administration of Tribulus terrestris extract and L-carnitine may reduce the efficacy since most of the studies with higher efficacies administered the compounds separately. In a study by Khademi et al (2004) L-carnitine was administered $3 \mathrm{~g} /$ day for three months to 65 males with infertility (Grade C progressively motile spermatozoa) in order to evaluate the sperm parameters; results showed a significant increase in sperm counts and significant decrease in the rate of morphological abnormalities.[17] However, in the study by Jehan et al (2012) on idiopathic infertility, L-carnitine plus multivitamin was administered to 139 males with infertility and results indicated that consumption of the two compounds simultaneously was more effective than their separate consumption.[8] Cheng et al (2008) showed that coadministration of L-carnitine and acetyl-carnitine as an alternative medicine can be effective to treat idiopathic asthenospermia and the quality of semen was improved following the consumption of the compounds.[22]

Salgado et al (2016) evaluated the effect of Tribulus terrestris extract capsules on semen parameters of 65 males with infertility. Results showed that consumption of Tribulus terrestris could significantly increase the concentration of semen as well as motility of spermatozoa and improve the time of turning from clotting form to liquid.[23] Nevertheless, in the study by Roaiah et al (2016) $750 \mathrm{mg}$ of Tribulus terrestris for three months was administered to patients and the results showed no significant changes between pre- and post-intervention measures in terms of semen parameters as well as total and free testosterone and serum level of LH.[24]

\section{CONCLUSION}

Based on the results of the current study, treatment with Tribulus terrestris extract and L-carnitine for three months could not improve abnormal parameters of spermatozoa in males with infertility. Owing to the results of other studies regarding the efficacy of the compounds consumed 
separately, further studies with larger sample sizes and longer interventions are recommended in order to compare the results obtained from co-administration of the compounds with those of their separate consumption.

\section{REFERENCES}

[1] Meletis CD, Barker J. Natural ways to enhance male fertility. Alternative \& Complementary Therapies 2004;10(1):22-7.

[2] Hall JE. Guyton and Hall textbook of medical physiology e-Book. Elsevier Health Science 2015.

[3] Vahidi S, Ardalan A, Mohammad K. Prevalence of primary infertility in the Islamic Republic of Iran in 2004-2005. Asia Pac J Public Health 2009,21(3):28793.

[4] Tanagho EA, McAninch JW. Smith's general urology. McGraw-Hill Medical 2007.

[5] Brugh VM, Lipshultz LI. Male factor infertility: evaluation and management. Med Clin North Am 2004;88(2):367-85.

[6] Jarow JP, Sharlip ID, Belker AM, et al. Best practice policies for male infertility. J Urol 2002;167(5):213844.

[7] Schiff JD, Ramírez ML, Bar-Chama N. Medical and surgical management male infertility. Endocrinology and Metabolism Clinics 2007;36(2):313-31.

[8] Aram JJ, Al-Shamma KJ, Al-Hassani AN. Effect of Lcarnitine, multivitamins and their combination in the treatment of idiopathic male infertility. Iraqi Journal of Pharmaceutical Sciences 2017;21(1):14-20.

[9] Moradi M, Moradi A, Alemi M, et al. Safety and efficacy of clomiphene citrate and L-carnitine in idiopathic male infertility: a comparative study. Urol J 2010;7(3):188-93.

[10] Peivandi S, Karimpour A, Moslemizadeh N. Effects of Lcarnitine on infertile men's spermogram; a randomized clinical trial. Journal of Reproduction \& Infertility 2010;10(4).

[11] Sheikh N, Goodarzi M, Bab Al-Havaejee H, et al. Lcarnitine level in seminal plasma of fertile and infertile men. J Res Health Sci 2007;7(1):43-8.

[12] Al-Yawer M, Hassan AJ, Haddad FYS, et al. Effects of AL-Qutub (Tribulus terrestris) on the spermatogenesis of the mouse testis: histological, histochemical and morphometrical studies. J Fac Med Baghdad 2008,50(2):246-54.

[13] Elahi RK, Asl S, Shahian F. Study on the effects of various doses of tribulus terrestris extract on epididymal sperm morphology and count in rat. Glob Veterin 2013;10(1):13-7.
[14] Singh S, Nair V, Gupta YK. Evaluation of the aphrodisiac activity of tribulus terrestris Linn. in sexually sluggish male albino rats. J Pharmacol Pharmacother 2012;3(1):43-7.

[15] Sellandi TM, Thakar AB, Baghel MS. Clinical study of tribulus terrestris Linn. in oligozoospermia: a double blind study. Ayu 2012;33(3):356-64.

[16] Setiawan L. Tribulus terrestris L. extract improves spermatozoa motility and increases the efficiency of acrosome reaction in subjects diagnosed with oligoastheno-teratozoospermia. Advances in Male Reproductive Physiology 1996;2:105-14.

[17] Khademi A, Safdarian L, Alleyassin A, et al. The effect of L-carnitine on sperm parameters in patients candidated for intracytoplasmic sperm injection. International Journal of Reproductive Bio Medicine 2004;2(2):65-9.

[18] Jashni HK, Shiravani SM, Hoshmand F. The effect of the tribulus terrestris extract on spermatogenesis in the rat. Journal of Jahrom University of Medical Sciences 2011;9(4):8-13.

[19] Stanislavov R, Nikolova V. Tribulus terrestris and human male fertility: I. Immunological aspects. Comptes Rendus de l'Academie Bulgare des Sciences 2000;53(10):107.

[20] Arsyad K. Effect of protodioscin on the quantity and quality of sperms from males with moderate idiopathic oligozoospermia. Medika 1996;22(8):614-8.

[21] Abo-Ghanema II, El-Nasharty MA, El-Far AH, et al. Effect of ginger and L-carnitine on the reproductive performance of male rats. World Academy of Science, Engineering and Technology 2012;6(4):215-21.

[22] Cheng H, Chen T. Clinical efficacy of combined Lcarnitine and acetyl-L-carnitine on idiopathic asthenospermia. Zhonghua Nan Ke Xue 2008;14(2):149-51.

[23] Salgado R, Marques-Silva M, Gonçalves E, et al. Effect of oral administration of tribulus terrestris extract on semen quality and body fat index of infertile men. Andrologia 2017;49(5).

[24] Roaiah MF, Elkhayat YI, Saleh SF, et al. Prospective analysis on the effect of botanical medicine (Tribulus terrestris) on Serum testosterone level and semen parameters in males with unexplained infertility. J Diet Suppl 2017;14(1):25-31. 